\title{
A crise da saúde mental
}

\section{The crisis of the mental health}

\author{
Fernando Antonio Mourão Flora \\ Psiquiatra e mestre, médico generalista da Prefeitura de Belo Horizonte (MG). Centro de Saúde Pompéia da Prefeitura de Belo Horizonte (MG). \\ Recebido: 04/06/2007 - Aceito: 08/10/2007 \\ Flora, F.A.M. / Rev. Psiq. Clin 35 (1); 33-34, 2008
}

Em nossa percepção, há uma crise na política de saúde mental em nosso meio. Destaquemos algumas questões críticas. Por falta de um tratamento adequado e/ou de adesão, um contingente significativo de portadores de transtorno mental recidiva com freqüência, permanecendo dependente dos serviços de saúde mental indefinidamente. Muitas vezes recebe, de rotina, um tratamento "burocrático": receitas de vários fármacos, em doses elevadas, repetidas ad nauseam. Quando esses pacientes estão em psicoterapia, tem-se a sensação de que se cumpre um monótono ritual, sem avanços evidentes. Fabricam-se toxicômanos menores com a prescrição indiscriminada de tranqüilizantes e hipnóticos, distribuídos como a fluoretação da água. Por outro lado, graves toxicômanos, como os alcoólatras, não recebem a atenção de que necessitam.

Diríamos que a luta "antimanicomial" desconstruiu - de forma ainda inacabada - o centro de gravidade do antigo modelo de saúde mental. O "processo estratégico de desinstitucionalização" implantou dispositivos substitutivos (Centro de Referência em Saúde Mental - Cersam, Centro de Convivência etc.) ao hospital psiquiátrico (Secretaria Municipal de Saúde de Belo Horizonte, 2006).

As crenças que alicerçam essa política em curso podem ser cunhadas do modelo socioanalítico. Sofrem de uma doença infantil compreensível, uma vez que lutam para se impor, denominada dogmatismo (Popper, 1978).

Ora, a ciência avança pela tensão entre os problemas existentes e as soluções experimentadas (Kuhn, 2001). Pelas críticas expostas, julgamos que a prática atual não está conseguindo responder aos complexos desafios da saúde mental em nossa sociedade capitalista periférica.

No entanto, a ciência do século XXI acumulou um conhecimento considerável em nossa compreensão do cérebro e da mente. Já foi dito, com ironia, que no Brasil "as idéias chegam com atraso, como se fossem queijos que necessitem envelhecimento...” (Campos, 1991).

Tomemos emprestado uma frase de Freud, invertendo-a: até aqui foi proveitoso caminhar ao lado dos psicanalistas, mas chegou a hora de voltar à ciência médica (Freud, 1948).

Henry Ey, o grande mestre da Psiquiatria francesa contemporânea, legou-nos um "testamento" precioso denominado O Nascimento da Psiquiatria (Ey, 1977). Neste artigo póstumo, critica a "mistificação" da doença mental que "consiste em negar sistematicamente a possibilidade mesmo de uma realidade clínica, a qual se manifesta, entretanto, na desordem da organização (de ordem natural e não somente moral ou ideológica)". Um dos eixos mais fundamentais da prática e da teoria da Psiquiatria há três séculos "é a relação das doenças mentais com a patologia cerebral, quer dizer com a desordem mesma da natureza humana ao nível de sua integração". Ou formulado de outra maneira: uma doença psiquiátrica é tão orgânica quanto uma doença neurológica (Brust, 2000). A Psiquiatria já foi descrita como uma Neurologia sem sinais. "O objeto da Psiquiatria, em suas relações prováveis com a patologia cerebral, certamente difere do 'fato neurológico', que pode ser definido como uma desintegração parcial dos instrumentos da vida de relação" (Ey, 1977). No debate com a Psicanálise, trata-se do choque com o "muro da biologia". Em sua polêmica com Jacques Lacan, Henry Ey argumenta que o conceito psicanalítico do inconsciente não consegue integrar a anomalia estrutural cerebral.

E deixa-nos suas últimas palavras: "A desorganização psicopatológica da natureza do homem não pode se descobrir em sua especificidade mórbida senão através de uma História Natural da Loucura: a história das idéias sobre os fundamentos da Psiquiatria só pode ser aquela de uma idéia sobre o desenvolvimento da organização e 
da desorganização do ser humano. Talvez tenha assim podido ajudar a melhor compreender o sentido e a verdade da Psiquiatria como ciência médica. Está na moda, em nossa época consagrada à idolatria da irracionalidade, questionar se a Psiquiatria não é vã e caduca - foi mesmo dito que ela era criminosa! De minha parte, não creio que seu destino esteja selado - como julgam alguns assim chamados 'Psiquiatras' - eu creio muito mais que seu nascimento ainda não terminou” (Ey, 1977).

A Psiquiatria não é mais uma disciplina sem efetivos métodos de diagnóstico e tratamento (Kandel et al., 1997). A etiologia da esquizofrenia, a mais misteriosa das doenças cerebrais, é discutida no Mental Health: A Report of the Surgeon General (Department of Health and Human Services, 1999). As pesquisas convergem para desordens no neurodesenvolvimento, que podem ter causas genéticas e/ou ambientais precoces, levando a alterações sutis no cérebro. Outrossim, fatores do meio, intervindo mais tarde, podem exacerbar a expressão de defeitos genéticos ou neurodesenvolvimentais. A compreensão corrente propõe que a esquizofrenia seja causada por uma vulnerabilidade genética, acoplada com agravos ambientais e psicossociais.

Nos países emergentes, em comparação com os países desenvolvidos, os pacientes com sintomas mentais são mais suscetíveis a alterações focais intracranianas, e a atrofia cerebral incide em idades mais precoces (Sartorius e Emsley, 2000). A alta incidência de abuso de substância e de traumatismo craniano é fator de risco, assim como o são as infecções cerebrais, tais como a Aids, a neurocisticercose e a sífilis nervosa (Sartorius e Emsley, 2000). A síndrome hipóxico-isquêmica perinatal constitui, com frequiência, dano precoce à saúde mental (Flora, 2002). E os fatores de risco se multiplicam, começando pela rubrica geral de "agravo maternal" (Department of Health and Human Services, 1999).

A Psiquiatria moderna depende de tecnologia avançada, como, por exemplo, técnicas de imagem cerebral para a identificação de prováveis lesões patológicas estruturais. Os novos agentes farmacológicos são muito mais eficazes e funcionam com maior margem de segurança no tratamento dos transtornos psicóticos, do humor, da ansiedade e outros (WHO, 2001; President's New Freedom Commission on Mental Health, 2005; Mackensie et al., 2005).

Entretanto, em virtude de seus custos significativos, esses avanços não estão amplamente acessíveis nos países emergentes (Sartorius e Emsley, 2000). Em conseqüência, a diferença de qualidade na prestação de serviços de saúde mental está cada vez mais se ampliando entre os países desenvolvidos e os emergentes. (mesmo no Primeiro Mundo, os tratamentos mais atualizados e efetivos, baseados em décadas de pesquisas, podem levar de 15 a 20 anos antes de se incorporarem à rotina de tratamento) (President's New Freedom Commission on Mental Health, 2005).

À guisa de conclusão, podemos afirmar que a pesquisa científica efetuou importantes progressos no conhecimento do cérebro e da mente, viabilizando tratamentos eficazes e estratégias de cuidado adequadas para muitas doenças mentais (President's New Freedom Commission on Mental Health, 2005). Não é mais possível se furtar a uma prática psiquiátrica baseada em evidências, ou seja, de eficácia bem documentada em rigorosas pesquisas clínicas. Henri Ey tinha razão: a Psiquiatria é bem uma especialidade da Medicina.

\section{Referências}

Belo Horizonte: publicação da Secretaria Municipal de Saúde. - A atenção básica de saúde em Belo Horizonte: recomendações para a organização local, p. 184, maio 2006.

Brust, J.C.M. - A Prática da Neurociência: das sinapses aos sintomas. Reichmann \& Affonso, Rio de Janeiro, p. 300, 2000.

Campos, R. In: Merquior, J.M. - 0 liberalismo, antigo e moderno. Nova Fronteira, Rio de Janeiro, p. 7, 1991.

Department of Health and Human Services. Mental Health: a report of the Surgeon General. Bethesda, Md: National Institute of Mental Health, 1999, chapter 4/sec 4.

Ey, H. - La Naissance de la Psychiatrie. In: Actualités Psychiatriques 5: 9-24, 1977.

Flora, F.A.M. - Autismo infantil e fatores de risco biológicos. Rev de Psiq Psican com Crianças e Adolescentes 3(9): 47-54, 2002.

Freud, S. Obras Completas. Editorial Biblioteca Nueva, Madrid, vol. II, p. $33,1948$.

Kandel, E.R.; Schwartz, J.H.; Jessel, T.M. Fundamentos da Neurociência e do Comportamento. Guanabara Koogan, Rio de Janeiro, p. 591, 1997.

Kuhn, T.S. - A estrutura das revoluções científicas. 6.ed., Perspectiva, São Paulo, p. 257, 2001.

Mackensie, T.D.; Kolpak, S.J.; Mehler, P.S.; Kessler, R.C.; Wang, P.; Zaslavsky, A.M. - Prevalence and Treatment of Mental Disorders, 1990 to 2003 . N Engl J Med 353: 1184, 2005. Popper, K.R. - Lógica das ciências sociais. Brasília: Ed. Universidade de Brasília, pp. 13-34, 1978.

President's New Freedom Commission on Mental Health. Achieving the promise: transforming mental health care in America, 2005.

Sartorius, N.; Emsley, R.A. - Psychiatry and technological advances: implications for developing countries. The Lancet 356: 2090-2092, 2000.

World Health Organization. - The World Health Report 2001 - Mental Health: New Understanding, New Hope, Geneva: World Health Organization, 2001. 